\title{
Flow artefact mimicking pulmonary embolism in pulmonary hypertension
}

\author{
Konstantinos Stefanidis, ${ }^{1}$ Jordan Green, ${ }^{1}$ Elissavet Konstantelou, ${ }^{2}$ Hasti Robbie ${ }^{1}$
}

${ }^{1}$ Radiology, King's College Hospital NHS Foundation Trust, London, UK

${ }^{2}$ 1st Department of Respiratory Medicine, Sotiria General Hospital, National and Kapodistrian University of Athens, Athens, Greece

Correspondence to Dr Konstantinos Stefanidis; kstefanidis@nhs.net

Accepted 15 February 2020
Check for updates

(c) BMJ Publishing Group Limited 2020. No commercial re-use. See rights and permissions. Published by BMJ.

To cite: Stefanidis K, Green J, Konstantelou $\mathrm{E}$, et al. BMJ Case Rep 2020;13:e234652. doi:10.1136/bcr-2020234652

\section{DESCRIPTION}

A 37-year-old man with a background of bronchiectasis secondary to common variable immunodeficiency (CVID) and pulmonary hypertension presented with dyspnoea, tachycardia and hypoxia. He was investigated with a CT pulmonary angiogram (CTPA) for suspected pulmonary embolus (PE). The CTPA was performed during inspiration using bolus-tracking technique $(60 \mathrm{~mL}$ of non-ionic contrast with a $100 \mathrm{~mL}$ saline chaser at $4.5 \mathrm{~mL} / \mathrm{s}$ with a time delay of $6 \mathrm{~s}$ ). This revealed a well-opacified pulmonary trunk (506 HU) with multiple filling defects in the main and lobar pulmonary arteries (figure $1 \mathrm{~A}-\mathrm{C}$ ). There was background CVID-related bronchiectasis and left lower lobe collapse (figure 1D). Initially, the reporting radiologist concluded that the CTPA was positive for acute pulmonary embolism. However, on further evaluation by specialist chest radiologist, it was noted that despite optimal opacification of the pulmonary trunk, there was layering of contrast in the lobar pulmonary arteries with a 'smoke-like' appearance (figure 1A,B). Turbulent flow artefact leading to suboptimal opacification of lobar and segmental pulmonary arteries was suspected. The CTPA was repeated in the resting expiratory position with more prolonged time delay (9s),

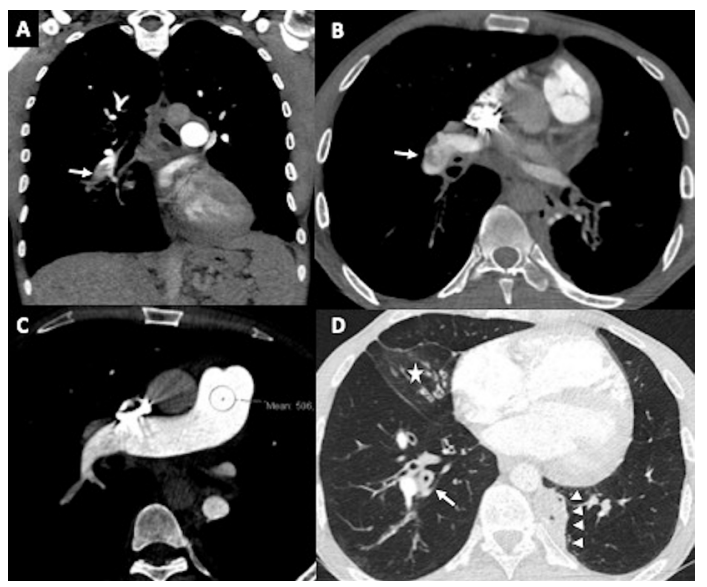

Figure $1 \quad(A, B)$ Coronal and axial images in the CT pulmonary angiogram showing ill-defined filling defects in a lobar pulmonary artery (arrows) of the right lower lobe. (C) Bolus-tracking technique with optimal opacification of the pulmonary trunk (HU 506). (D) Axial CT image showing bronchiectasis with bronchial wall thickening (arrow), left lower lobe collapse (arrowheads) and partial middle lobe collapse (asterisk) in the background of common variable immunodeficiency. showing homogeneous opacification of the pulmonary arteries and excluding pulmonary embolism (figure 2).

A number of diagnostic pitfalls have been described in the diagnosis of pulmonary embolism on CT. ${ }^{1}$ These include technical problems caused by improper bolus timing, respiratory motion artefact, streak artefact, patient body habitus and misinterpretation of normal bronchovascular anatomy. Physiological and pathological processes may alter the contrast kinetics resulting in suboptimal opacification of the vessels. In our case, despite the bolustracking method, there was inadequate scanning time delay resulting in suboptimal enhancement of the pulmonary arteries. While bolus-tracking technique aims to maximise contrast in the vessel of interest, early scanning may lead to incomplete mixing of contrast and blood in the vessels distal to the target vessel, leading to suboptimal opacification. The appearances resemble a puff of smoke, a term used by the cardiologists to describe slow flow in echo. ${ }^{2}$ The smoke-like appearance with turbulent flow has been previously described in a limited

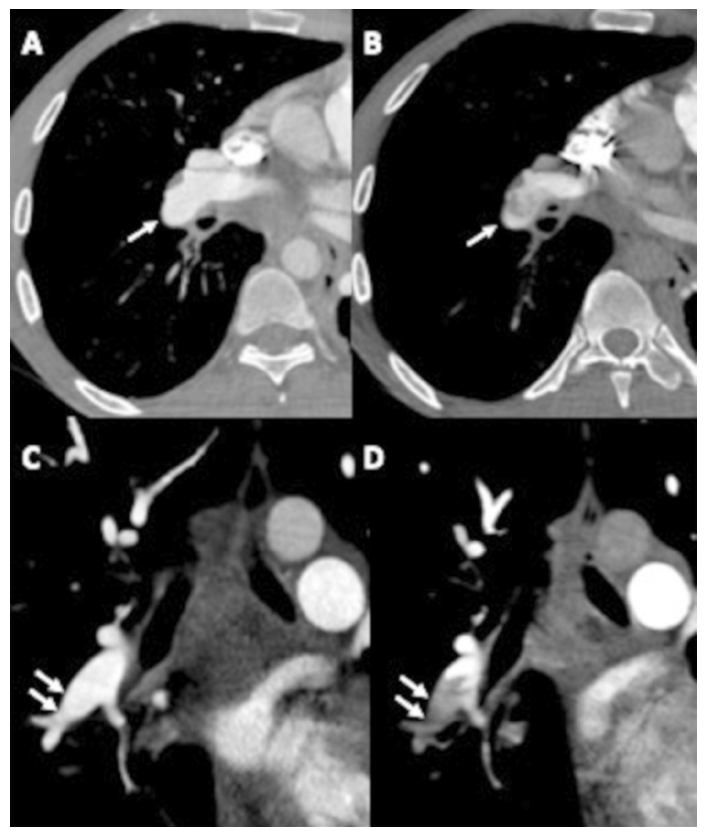

Figure 2 Initial $(A, C)$ and repeat CTPA studies in our case $(B, D)$. The CTPA $(A, C)$ was repeated with more delayed injection of contrast and during expiration showing homogeneous opacification of the pulmonary arteries (arrows) in axial and coronal CT images. The initial CTPA $(B, D)$ at the same level in axial and coronal reconstructions shows the flow artefacts (arrows) mimicking emboli. CTPA, CT pulmonary angiogram. 
number of patients with pulmonary hypertension. ${ }^{3}$ Similar to our patient, the reported cases have backgrounds of pulmonary hypertension, which can probably explain the turbulent flow. These haemodynamic changes were confirmed in patients with pulmonary hypertension with MRI. ${ }^{4}$

Flow artefacts make interpretation of CTPA difficult, leading to false-positive results for PE. The basic CT characteristics in distinguishing true emboli from pseudoemboli are well-defined margins and contrast attenuation in the range of 30-60 HU for pulmonary emboli. ${ }^{5}$ Multiplanar reconstructions can help in distinguishing between flow artefacts and true emboli as they can better illustrate the borders of the filling defects. When flow artefact is suspected, a repeat expiratory CTPA with more delayed and prolonged contrast injection is recommended. ${ }^{6-8}$

\section{Learning points}

- Recognition of flow artefacts in interpretation of CT pulmonary angiogram (CTPA) examinations is important to reduce false-positive results and unnecessary anticoagulation therapy.

- Conditions such as pulmonary hypertension or cardiac failure may alter the contrast kinetics in CTPA examinations, resulting in suboptimal opacification of the pulmonary arteries. Appropriate modification of the scanning protocol with more delayed and prolonged contrast injection will resolve this artefact.
Contributors Identification of the case: KS. Conception and design: KS and HR. Literature search: KS, HR, EK and JG. Drafting of the manuscript: KS and HR. Critical revision of the manuscript for important intellectual content: HR, KS, EK and JG. Final approval of the version to be published: $\mathrm{KS}, \mathrm{JG}$, EK and HR.

Funding The authors have not declared a specific grant for this research from any funding agency in the public, commercial or not-for-profit sectors.

Competing interests None declared.

Patient consent for publication Obtained.

Provenance and peer review Not commissioned; externally peer reviewed.

\section{REFERENCES}

1 Aviram G, Levy G, Fishman JE, et al. Pitfalls in the diagnosis of acute pulmonary embolism on spiral computer tomography. Curr Probl Diagn Radiol 2004;33:74-84.

2 Merino A, Hauptman P, Badimon L, et al. Echocardiographic "smoke" is produced by an interaction of erythrocytes and plasma proteins modulated by shear forces. J Am Coll Cardiol 1992;20:1661-8

3 Pascoe HM, Pascoe D, McCusker MW, et al. Turbulent flow artefact mimicking central pulmonary emboli in pulmonary hypertension: a report of two cases. J Med Imaging Radiat Oncol 2019;63:481-3.

4 Reiter U, Reiter G, Fuchsjäger M. MR phase-contrast imaging in pulmonary hypertension. Br J Radiol 2016;89:20150995.

5 Henry TS, Hammer MM, Little BP, et al. Smoke: how to differentiate flow-related artifacts from pathology on thoracic computed tomographic angiography. J Thorac Imaging 2019;34:W109-20.

6 Remy-Jardin M, Remy J, Artaud D, et al. Spiral CT of pulmonary embolism: diagnostic approach, interpretive pitfalls and current indications. Eur Radiol 1998;8:1376-90.

7 Mortimer AM, Singh RK, Hughes J, et al. Use of expiratory CT pulmonary angiography to reduce inspiration and breath-hold associated artefact: contrast dynamics and implications for scan protocol. Clin Radiol 2011;66:1159-66.

8 Raczeck P, Minko P, Graeber S, et al. Influence of respiratory position on contrast attenuation in pulmonary CT angiography: a prospective randomized clinical trial. AJR Am J Roentgenol 2016;206:481-6.

Copyright 2020 BMJ Publishing Group. All rights reserved. For permission to reuse any of this content visit https://www.bmj.com/company/products-services/rights-and-licensing/permissions/

BMJ Case Report Fellows may re-use this article for personal use and teaching without any further permission.

Become a Fellow of BMJ Case Reports today and you can:

- Submit as many cases as you like

- Enjoy fast sympathetic peer review and rapid publication of accepted articles

- Access all the published articles

- Re-use any of the published material for personal use and teaching without further permission

Customer Service

If you have any further queries about your subscription, please contact our customer services team on +44 (0) 2071111105 or via email at support@bmj.com.

Visit casereports.bmj.com for more articles like this and to become a Fellow 